\section{SUMMARY OF RESEARCH REPORT: FOREIGN LANGUAGE TEACHING IN THE NORTHERN PART OF THAILAND}

\section{Anek Kimsuvan $^{1}$}

This research report synthesized the research data on foreign language education and use in northern Thailand. The project was conducted by seven different research groups working toward the same underlying objectives, namely to explore the current state of foreign language education and use at all academic levels and to examine satisfaction, needs, and problems related to foreign language use in the business sector in northern Thailand.

The sample for the project included those from the business sector (owners/staff heads and staff workers) and from the academic arena (administrators, teachers, and learners of foreign languages). The total number of the sample was 1,486 . Purposive sampling and simple random sampling methods were used in different stages of sampling in an attempt to capture sample subjects for as many different foreign languages, types of institutions, and businesses as possible.

The research data showed that eight foreign languages have been taught in Northern Thailand: English, French, German, Japanese, Korean, Mandarin, Burmese, and Vietnamese. English and Mandarin were taught at all levels of education and academic institutions. Unlike English, Mandarin was taught in Chinese schools

\footnotetext{
${ }^{1}$ Ph.D., Associate Professor, Faculty of Humanities, Chiang Mai University
}

at the primary level (class 1 to class 4). From class 5, English was offered in Chinese schools. Vietnamese and Korean were taught intermittently in some institutions.

Most foreign language teachers were Thai. In the sample, most secondary, high school, and vocational school teachers had their B.A. in English; however, only $16 \%$ of primary school instructors had such a degree. A great number of them used Thai as a medium of instruction and were most proficient in reading and least proficient in speaking and listening.

From one point of view, the data from school administrators showed a lack of foreign language teachers at all levels and no budget for employing teachers. From another perspective, the data from foreign language teachers reflected their teaching and working load. Apart from the typical problems of huge class size, other factors were learners' poor foreign language background, and lack of learning enthusiasm, confidence, and courage to perform language tasks. One of the primary concerns relating to teaching was the absence of clarity in the curriculum. Though $90-95 \%$ of the high school teachers participated in the evaluation and improvement of the curriculum, they complained that they could not comprehend it.

The learners were rarely exposed to any language use in their daily life outside the classroom. Neither did they fully practice their language skills in class due to the excessive number of students in each class and the small number of classroom sessions. They were also rarely offered outside classroom activities for promoting their language proficiency. Learning behaviors mostly focused on regular class attendance 
and practice of language exercises. The activity that learners mostly used to practice their foreign languages involved examinations. Their aim in learning was to pass the examination. N ot many of them reported the use of other learning resources for their self-study. The students were most capable of reading and least proficient in speaking and listening, thus needing much improvement in these two skills as did most of their teachers. The students of all foreign languages in the university learned r eading and writing. Most of the learners had a positive attitude toward foreign languages.

The data for the business sector sample revealed that the foreign language used and needed most was English, followed by Mandarin and Japanese respectively. Burmese and Korean were becoming important because of the increase in industry, the presence of foreign workers, and the policy of national security. The business sector, the administrators and the university instructors knew the trends in the required languages, but the students lacked this information. The language skills required most were speaking and listening, and most employers showed little satisfaction with the personnel's language competency. Employees were very dissatisfied with their speaking and listening skills. The employees' most needed vocabulary was in the fields of tourism, computer, information technology, finance, culture, and education. Work which required foreign languages involved inquiries, information operations, services, and marketing.

Suggestions from the project working groups include: Madarin and Japanese should be chosen as foreign languages, since they are as important as English. The teaching of all languages must emphasize speaking and listening skills. The ministry of labour, the ministry of education, and the office of higher learning should work together in order to get a focused idea for improving the curriculum that suits the needs of the labor market. 